\title{
Proton-conducting Organic-inorganic Sulfo-containing Membranes for Fuel Cells
}

\section{Inga GRIGORAVICIUTE-PURONIENE ${ }^{1}$ *, Iryna YEVCHUK ${ }^{2}$, Oksana DEMCHYNA ${ }^{2}$, Mariia ZHYHAILO ${ }^{2}$, Khrystyna RYMSHA ${ }^{2}$, Natalia BABKINA ${ }^{3}$, Tetyana SHANTALIY ${ }^{3}$, Bogdan RACHIY ${ }^{4}$, Aivaras KAREIVA ${ }^{1}$, Zivile STANKEVICIUTE ${ }^{1}$, Ramunas SKAUDZIUS ${ }^{1}$, Aleksej ZARKOV ${ }^{1}$, Rostyslav MUSIY ${ }^{2}$}

\author{
${ }^{1}$ Institute of Chemistry, Faculty of Chemistry and Geosciences, Vilnius University, Naugarduko st. 24, LT-03225 Vilnius, \\ Lithuania \\ ${ }^{2}$ Department of Physical Chemistry of Fuel Fossils L.M. Lytvynenko Institute of Physico-organic Chemistry and Coal \\ Chemistry NAS of Ukraine, 3a Naukova Street, 79060 Lviv, Ukraine \\ ${ }^{3}$ Institute of Macromolecular Chemistry NAS of Ukraine, Kharkivske shaussee, 48, 02160 Kyiv, Ukraine \\ ${ }^{4}$ Vasyl Srefanyk Precarpathian National University, Shevchenko Str., 57, 76000 Ivano-Frankivsk, Ukraine
}

crossref http://dx.doi.org/10.5755/j02.ms.28440

Received 01 February 2021; accepted 01 April 2021

\begin{abstract}
Cross-linked organic-inorganic sulfo-containing membranes of various compositions based on acrylic monomers (acrylonitrile, acrylic acid, 3-sulfopropylacrylate potassium salt, ethylene glycol diacrylate) and sol-gel systems of tetraethoxysilane have been developed. Synthesis of the polymer matrix was carried out by UV-initiated polymerization of the monomer mixture and the inorganic component was formed in situ while conducting the sol-gel process of the precursor. FTIR, SEM, EDS, DMA, impedance spectroscopy were used to characterize the synthesized materials. The influence of inorganic component content on the properties of the membranes was investigated. DMA results show that an increase in silica content leads to a decrease in packing density and an increase in structural heterogeneity in sulfocontaining polyacrylate/silica membranes. The highest values of proton conductivity $1.12 \cdot 10^{-2} \mathrm{Sm} / \mathrm{cm}$ at $60{ }^{\circ} \mathrm{C}$ were found in membranes containing $3 \mathrm{wt} . \%$. of the added sol-gel system. Further increase of silica content does not increase the proton conductivity of the membranes. The proton transfer activation energies in the membranes were calculated from the temperature dependence of proton conductivity. The obtained cross-linked sulfo-containing organic-inorganic materials can be used for the development of proton-conducting membranes for fuel cells.

Keywords: proton conductive membrane, organic-inorganic nanocomposite, sulfo-containing monomer, sol-gel method, impedance spectroscopy.
\end{abstract}

\section{INTRODUCTION}

Nowadays, one of the major problems is the search for new technologies with the goal to obtain cheap energy since scientists have estimated that fossil resources will be depleted in the coming decades. Several countries, including Japan, Norway, the Netherlands, France, the United Kingdom, Germany, South Korea, and others have adopted long-term programs for the development of hydrogen technologies. Hydrogen energy can be generated in fuel cells whose key element is the proton-conducting membrane (PEM). Investigations on the creation of efficient and inexpensive polyelectrolyte membranes for fuel cells are developed dynamically [1-4].

The most common PEM-material currently seems to be the sulfonated fluoropolymer Nafion (Du Pont). This type of membrane has many advantages compared to other PEMs: high mechanical strength, heat resistance, chemical inertness, and high proton conductivity. The disadvantages of these membranes include a limited range of operating temperatures (they lose efficiency at elevated temperatures), a significant methanol crossover, and high cost. Therefore,

\footnotetext{
* Corresponding author. Tel.: +370-5-2193107.

E-mail address: inga.grigoraviciute@chf.vu.lt (I. GrigoraviciutePuroniene)
}

the search for new effective proton-conducting membranes is ongoing.

PEMs can be made from organic-inorganic materials. Quite often, a sol-gel method is used for the synthesis of hybrid organic-inorganic membranes. As a result of the solgel conversion of alkoxysilane precursor, 3D a crosslinked silica gel matrix with $\mathrm{Si}-\mathrm{O}$ bonds is formed. Crosslinking is a simple and effective way to control the stability of the dimensions, the swelling behaviour, and the prevention of fuel permeability. If the sol-gel process occurs simultaneously with the polymerization process of organic monomers, it is possible to obtain a polymer-inorganic hybrid, in which the organic polymer and the inorganic gel will be mutually dispersed at the nanoscale.

An interesting way to synthesize organic-inorganic membranes using the sol-gel method is described in [5]: simultaneously with polymerization of 3-glycidoxypropyl trimethoxysilane (GPTMS), a sol-gel process involving 3glycidoxypropyl trimethoxysilane (GPTMS) and 3mercaptopropyl trimethoxysilane (MPTMS) occurs. -SH groups of MPTMS are oxidized to sulfo groups, which provide the proton conductivity of the hybrid membranes. The authors [6] developed novel PEMs based on organic- 
inorganic copolymers synthesized from 3-glycidoxypropyl trimethoxysilane (GPTMS), sulfonated phenyltriethoxysilane (SPS), tetraethoxysilane (TEOS) and $\mathrm{H}_{3} \mathrm{PO}_{4}$. These membranes possess high proton conductivity $\left(3.6 \cdot 10^{-2} \mathrm{Sm} / \mathrm{cm}\right.$ at $\left.120^{\circ} \mathrm{C}\right)$, mechanical strength, dense structure, thermal stability and therefore have considerable potential for use in fuel cells. New proton-conducting membranes based on sulfo-containing copolymers styreneallylglycidylether and tetraethoxysilane were obtained by the sol-gel method [7]. Hybrid composites have good elasticity, thermal and chemical stability, their proton conductivity is $1.46 \cdot 10^{-3} \mathrm{~S} / \mathrm{cm}$.

In the present work, acrylic monomers and a sol-gel system based on tetraethoxysilane (TEOS) were used to synthesize proton-conducting membranes by photoinitiated polymerization. The possibility of tuning the properties of polyacrylate/silica membranes by changing the ratio of organic matrix - sol-gel precursor was shown.

\section{EXPERIMENTAL}

Reagents acrylonitrile (AN), acrylic acid (AA), potassium salt of 3-sulfopropylacrylate (SPAK), tetraethoxysilane (TEOS), ethylene glycol diacrylate (EGDA), and photoinitiator 2,2-dimethoxy-2phenylacetophenone (DMPA) were purchased from Aldrich and used without further purification. The objects of the study were polyacrylate and polyacrylate/silica membranes obtained by the method of photoinitiated polymerization of monomer mixture with the simultaneous sol-gel reaction in the sol-gel system based on TEOS. The scheme of the synthesis of polymer membrane is shown in Fig. 1.

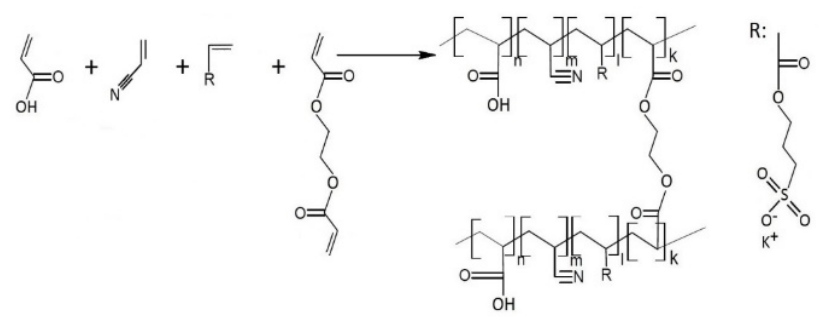

Fig. 1. Scheme of polymer matrix synthesis

The synthesis of membranes was carried out according to the following procedure, similar to that in $[8,9]$ : an aqueous solution containing water-soluble reagents (AA, SPAK and EGDA) was mixed with the corresponding amount of AN in which the photoinitiator was dissolved. The whole mixture was stirred on a magnetic stirrer for 35 min (500 rpm). The ratio of reagents in feed compositions for polymerization is given in Table 1 . In addition, the polymerization mixture included a photoinitiator DMPA (2.0 wt. \%).

The sol-gel solution of the precursor was prepared separately, mixing TEOS, ethanol, water and phosphoric acid (sol-gel process catalyst) in the following ratios 1:4:2:1.8 (mol). The sol-gel system was stirred continuously (500 rpm) in a water bath at $50{ }^{\circ} \mathrm{C}$ for $35 \mathrm{~min}$. Then, the appropriate volume of sol-gel precursor solution was added to the mixture of monomers. Next, the entire mixture was placed in a glass form $(50 \mathrm{~mm} \times 20 \mathrm{~mm} \times 0.15 \mathrm{~mm})$ and covered with glass plates to prevent the inhibition of polymerization with oxygen. The prepared compositions were subjected to UV irradiation with a mercury-quartz lamp DRT-400 with a power of $14 \mathrm{~W} / \mathrm{m}^{2}$. The wavelength of irradiation was $365 \mathrm{~nm}$, the irradiation time was $20 \mathrm{~min}$, and the distance between the sample and the light source was $5 \mathrm{~cm}$. The obtained samples were washed in distilled water and dried at $40{ }^{\circ} \mathrm{C}$ untill constant weight.

Table 1. Feed composition for proton-conducting membrane synthesis

\begin{tabular}{|c|c|c|c|c|c|}
\hline $\begin{array}{c}\text { Sample, } \\
\text { wt.\% }\end{array}$ & S1 & S2 & S3 & S4 & S5 \\
\hline SPAK & 25.0 & 24,8 & 24.3 & 23.8 & 23.2 \\
\hline AA & 15.0 & 14.9 & 14.5 & 14.2 & 14.0 \\
\hline AN & 33.0 & 32.6 & 32.0 & 31.4 & 30.7 \\
\hline EGDA & 27.0 & 26.7 & 26.2 & 25.6 & 25.1 \\
\hline SGS & - & 1.0 & 3.0 & 5.0 & 7.0 \\
\hline
\end{tabular}

The morphology of the membranes was examined by EVO 40XVP scanning electron microscope. Quantitative elemental microanalysis was performed using INCA Energy 350 energy dispersive X-ray spectrometer. IR spectra of the membranes were recorded using a spectrometer Nicolet IS 10 ATR with a resolution of $10 \mathrm{~cm}^{-1}$ in the spectral range of $4400-400 \mathrm{~cm}^{-1}$.

Dynamic mechanical analysis (DMA) of the synthesized membrane samples was performed on DMA Q800 (TA Instruments, USA) in the tensile mode at a forced sinusoidal oscillation frequency of $10 \mathrm{~Hz}$ in the temperature range $20-200^{\circ} \mathrm{C}$. The heating rate was $3^{\circ} \mathrm{C} / \mathrm{min}$.

Impedance hodographs Z' = $\mathrm{f}$ (Z'), where Z' and Z',are respectively the real and imaginary part of the complex resistance of the system $(Z=Z$ ' $-j Z$ ', $j$ is the imaginary unit), were obtained using the Autolab/FRA-2 (the Netherlands) in the frequency range of $10-10^{5} \mathrm{~Hz}$. The amplitude of the sinusoidal voltage was equal to $10 \mathrm{mV}$, the temperature measurement interval was $20-60^{\circ} \mathrm{C}$. The tested sample was placed between two platinum electrodes. Prior to the measurements, the membranes were soaked in $0.1 \mathrm{M} \mathrm{HCl}$ to replace $\mathrm{K}^{+}$ions with protons and then sandwiched between two Pt electrodes. Taking into account the geometrical parameters of the samples, the values of the specific proton conductance were calculated using equation:

$\sigma=l / R S, \mathrm{Sm} / \mathrm{cm}$,

where $R$ is the sample resistance, Ohm; $l$ is the thickness of the specimen, cm; $S$ is the electrode - sample contact area, $\mathrm{cm}^{2}$. Prior to the measurements, the membranes were soaked in $0.1 \mathrm{M} \mathrm{HCl}$ to replace $\mathrm{K}^{+}$ions with protons and then sandwiched between two Pt electrodes.

The activation energy of proton transfer was calculated from the temperature dependence of proton conductivity using the Arrhenius equation:

$\sigma=A \exp \left(-\frac{E}{k T}\right)$

where $\sigma$ is the proton conductivity; $T$ is the absolute temperature; $k$ is the Boltzmann constant; $A$ is the preexponential factor; $E$ is the activation energy [10].

\section{RESULTS AND DISCUSSION}

UV-cured membranes with a thickness of $100-150 \mu \mathrm{m}$ 
were transparent and elastic. When UV irradiation of the feed compositions was carried out hydrolysis of tetraethoxysilane with subsequent condensation of silanol groups occured in situ simultaneously with the polymerization process of monomers resulting in the formation of a joint organic-inorganic structure of the nanocomposite due to hydrogen bonds.

IR spectra, given in Fig. 2, allowed us to confirm the chemical composition of the polymer matrix and introduction of the inorganic counterpart. As expected, the representative spectra of the membranes show the analogous assignment: the main bands can be attributed to the functional groups of the polymeric matrix, which forms the major part of all samples. The fact that the measured IR spectra of all samples exhibit similar peaks at the same wavenumbers indicates a uniform distribution of component domains within the membranes and the absence of significant phase segregation.

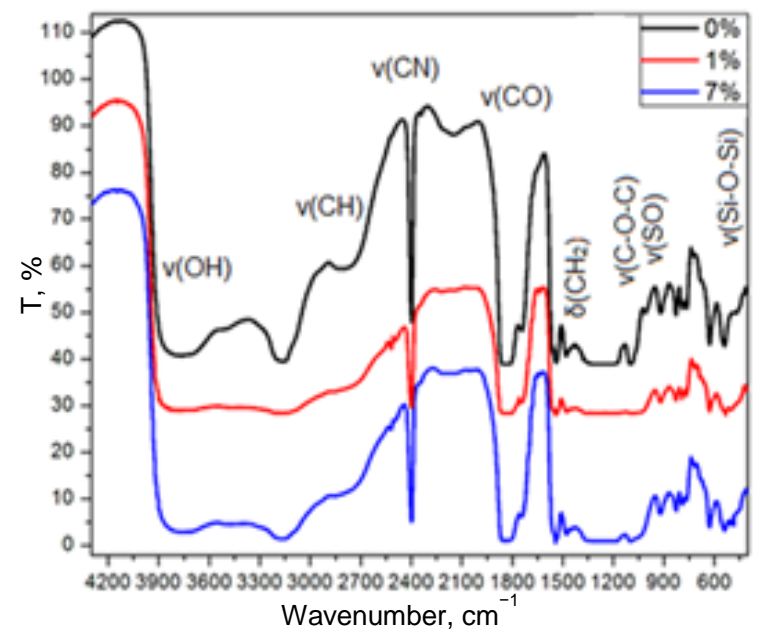

Fig. 2. IR spectra of membranes

The broad peak is observed in the region of $3900-3400 \mathrm{~cm}^{-1}$ and it may be assigned to $-\mathrm{OH}$ groups stretching vibrations of the acrylic acid carbonyl group and the chemically bounded water $[11,12]$. It should be noted that the band was intensified due to the incorporation of the inorganic component in the polymer matrix. The absorption band in the range $2700-2500 \mathrm{~cm}^{-1}$ is associated with $\mathrm{C}-\mathrm{H}$ vibrations of $\mathrm{CH}_{\mathrm{n}}$ groups. The absorption peak at $2243 \mathrm{~cm}^{-1}$ corresponds to the stretching vibrations of the nitrile group present in acrylonitrile. The broad absorption band with peaks at 1634 and $1731 \mathrm{~cm}^{-1}$ is attributed to the vibrational stretching of intermolecular hydrogen bonds between carbonyl groups and free stretching vibrations of the carbonyl group, respectively [13]. In all spectra there is a peak at $1124 \mathrm{~cm}^{-1}$, which is attributed to $\mathrm{C}-\mathrm{O}-\mathrm{C}$ stretching and inherent in the spectrum poly(EGDA).The asymmetric vibrations $v(\mathrm{SO})$ of the sulfonic acid group contained in SPAK are observed as the bands at 1040 and $1168 \mathrm{~cm}^{-1}$ [14].

Spectra demonstrate the presence of silica. At $1020 \mathrm{~cm}^{-1}$, a gentle absorption peak is observed due to asymmetric vibrations of the $\mathrm{Si}-\mathrm{O}-\mathrm{Si}$ groups, which is well noticeable in the membrane containing 7 wt.\% of the SGS and are partially overlapped by the vibration absorption band $v(\mathrm{SO})$ in the membrane with 1 wt.\% SGS. The spectra also show an increase in the peak intensity at $460 \mathrm{~cm}^{-1}$ with the addition of an inorganic component, which is also attributed to the asymmetric vibrations of the $\mathrm{Si}-\mathrm{O}-\mathrm{Si}$ groups $[15,16]$. The presence of the peak due to $\mathrm{Si}-\mathrm{O}-\mathrm{Si}$ group vibrations confirms the passing of precursor hydrolysis and condensation of $\mathrm{Si}(\mathrm{OR})_{\mathrm{x}}(\mathrm{OH})_{\mathrm{y}}$ species, which provides the formation of a cross-linked silica network in membranes.

The morphology of the membrane samples was determined by means of electron scanning spectroscopy. SEM images of the cross-section of polyacrylate and polyacrylate/silica membranes with different silica content (Fig. 3) confirm that the structure of the materials is homogeneous without visible phase separation. Individual pores of no more than $2 \mu \mathrm{m}$ in size can be visualized. Membrane S5, judging from the image, has a somewhat uneven structure, which may be due to the formation of large silica domains. Therefore, we conclude that the optimum content of added SGS is $5 \mathrm{wt} . \%$.
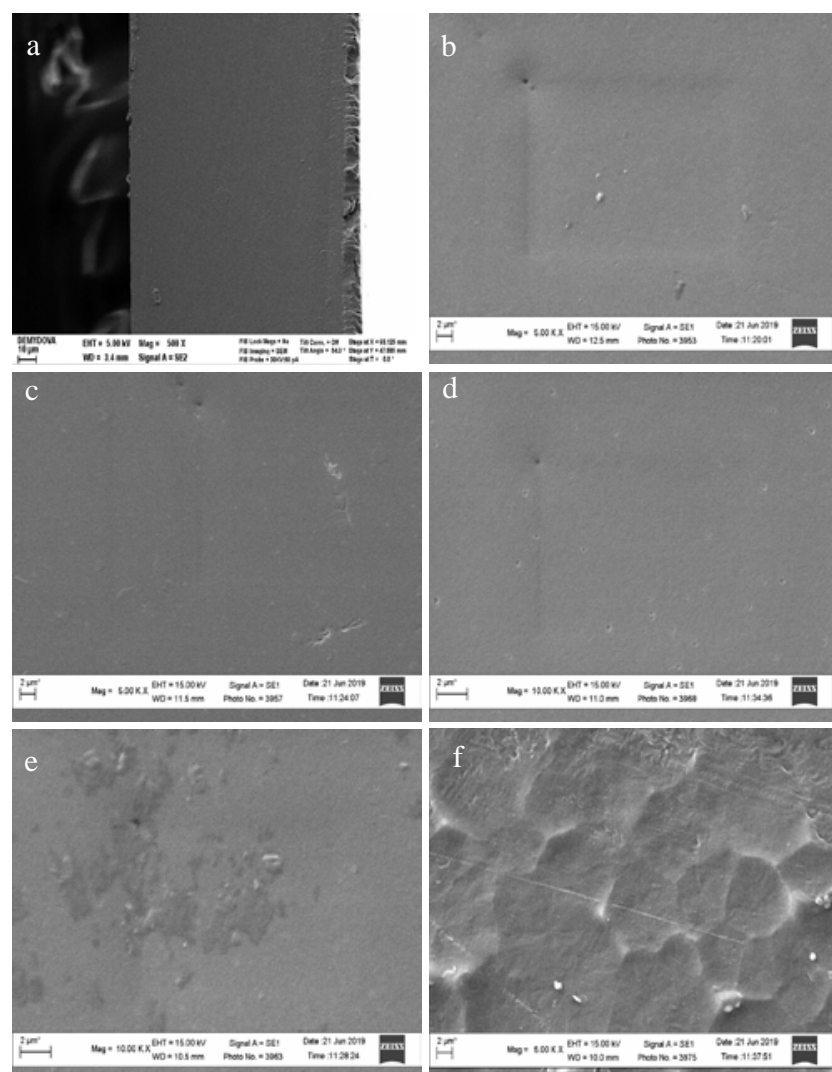

Fig. 3. SEM images of membranes: a - cross-sectional overview; close-view b-S1; c-S2; d-S3; e-S4; f-S5

In energy dispersive spectrometry (EDS) spectra of polymeric S1 and hybrid S2 membranes observed: an intense peak at $0.3 \mathrm{keV}$ corresponding to Carbon atoms, peaks of average intensity at $0.55,3.3$ and $2.3 \mathrm{keV}$ correspond to Oxygen (O), Potassium (K) and Sulfur (S). An EDS confirmed the existence of silica in the hybrid membrane. A clear signal corresponding to silicon (Si) atom was present at $1.75 \mathrm{keV}$ [9] in the EDS spectrum of hybrid membranes, whereas there was no signal in the pristine membrane (Fig. 4).

It is known that DMA is one of the most common methods of obtaining the correlation between the structure and properties of polymeric materials [17], including proton conducting membranes [18]. The results of DMA analysis show the dependence of the viscoelastic properties of the 
investigated membranes - modulus of elasticity ( $\left.E^{\prime}\right)$, loss modulus ( $\left.E^{\prime \prime}\right)$, and coefficient of mechanical loss $(\tan \delta)$ with temperature change.

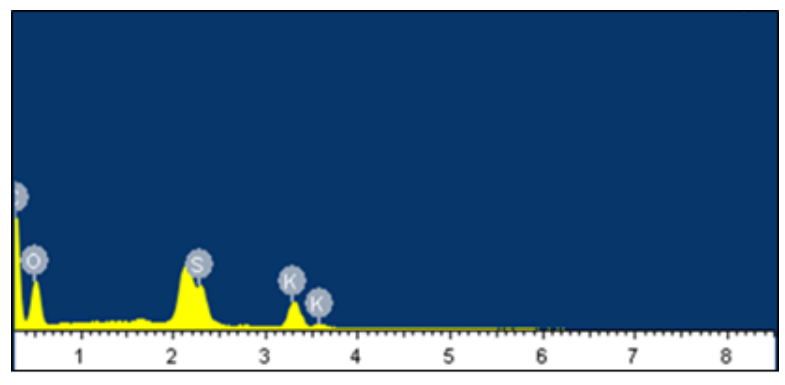

a

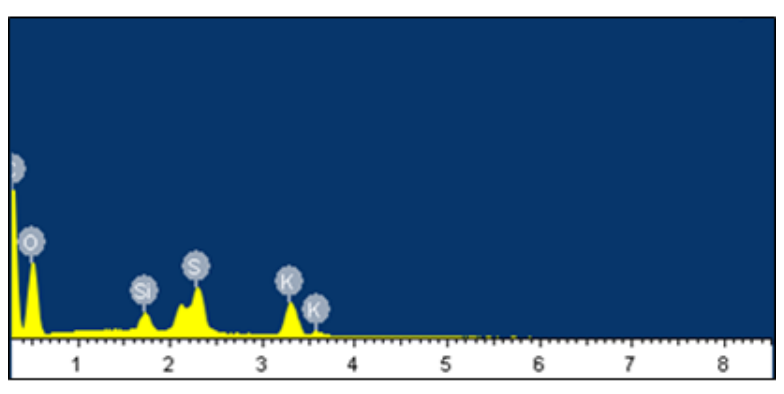

b

Fig. 4. EDS-spectra: $\mathrm{a}-\mathrm{S} 1$; b-S2 membranes

Fig. 5 shows that the initial matrix (sample S1) has two relaxation transitions: two regions of $E^{\prime}$ falling in the temperature range of $50-90^{\circ} \mathrm{C}$ and $30-170{ }^{\circ} \mathrm{C}$ (Fig. 5 a), two relaxation maxima on the temperature dependence of $E^{\prime \prime}$ (Fig. 5 b), and the dependence of $\tan \delta(T)$ has a clear maximum at $T=170{ }^{\circ} \mathrm{C}$ and a pronounced shoulder in the temperature range of $65-105^{\circ} \mathrm{C}$ (Fig. 5 c). Therefore, the original polyacrylate sulfo-containing matrix is a statistical copolymer whose structure consists of both rigid fragments and more flexible sections. The high-temperature relaxation maximum in the region near $170^{\circ} \mathrm{C}$ is the main relaxation glass transition and corresponds to the rigid regions in which mobility is significantly restricted due to cross-linking of EGDA chains (see Fig. 1). The low-temperature relaxation transition can be related to the mobility of both SPAK side chains and the long linear sections consisting of AA, AN, and SPAK monomers, forming terminal or individual chains.

Fig. 5 shows that the viscoelastic dependences of the polyacrylate matrix S1 and the hybrid membranes S2 - S5 are similar in shape of the curves, indicating the similarity of their phase morphology. At the same time, for the membranes S2 - S5, the value of the modulus of elasticity (Fig. 5 a) is significantly reduced, which may indicate a weakening of the intermolecular bonds and a decrease in the packing density in the polymer matrix, and this tendency is observed as the content of the inorganic component increases. For the polyacrylate/silica membranes, there is also a decrease in the intensity of the high-temperature relaxation maximum of $\tan \delta$ (Fig. 5 c), which can be explained by the blockage of the mobility of several segments in rigid fragments with the simultaneous formation of crosslinks between the copolymer chains. Thus, the results of DMA studies have shown that the introduction and increase of silica content lead to a decrease in packing density and an increase in structural heterogeneity in sulfo-containing polyacrylate/silica membranes.

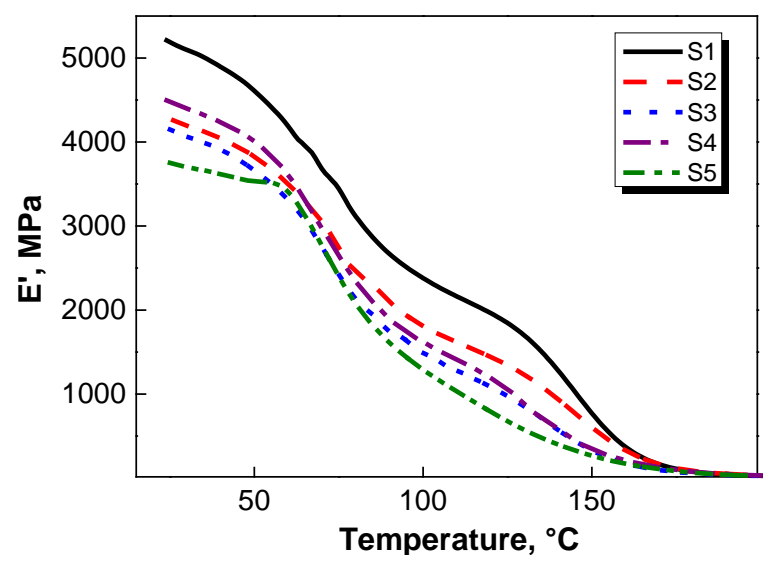

a

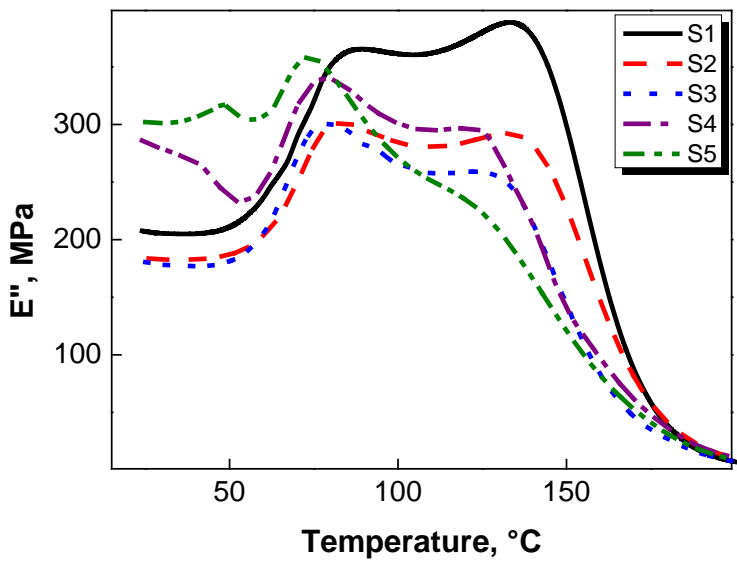

b

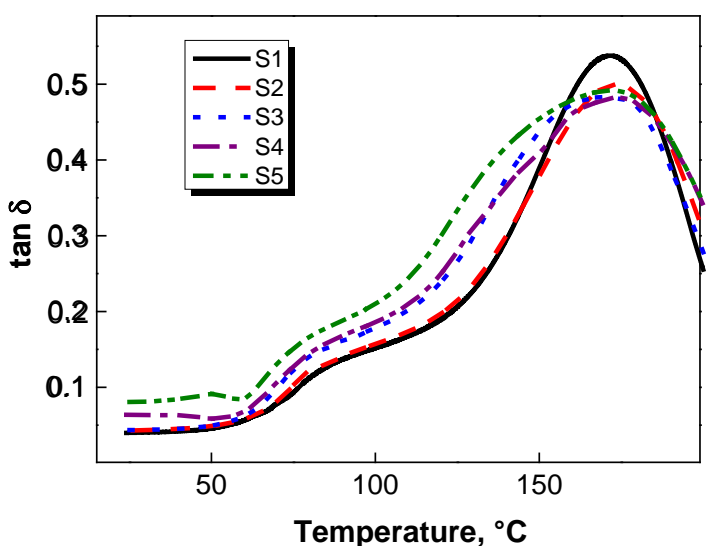

C

Fig. 5. Temperature dependences of: a $-E^{\prime}$; $\mathrm{b}-E^{\prime \prime}$; $\mathrm{c}-\tan \delta$ for the membranes S1 - S5

The most characteristic feature of the membranes used in fuel cells is their proton conductivity. The values of proton conductivity of membrane samples in the temperature range of $20-60{ }^{\circ} \mathrm{C}$, calculated from impedance measurements (Fig. 6), are given in Table 2.

The experimentally obtained results show that the proton conductivity of the membranes depends on their composition and temperature. Indeed, increasing the 
temperature increases the free volume of the system, structural disorientation, intensifies the segmental movement of polymer molecules, increases the water uptake and mobility of water and protons, which promotes proton transport and thus increases proton conductivity.

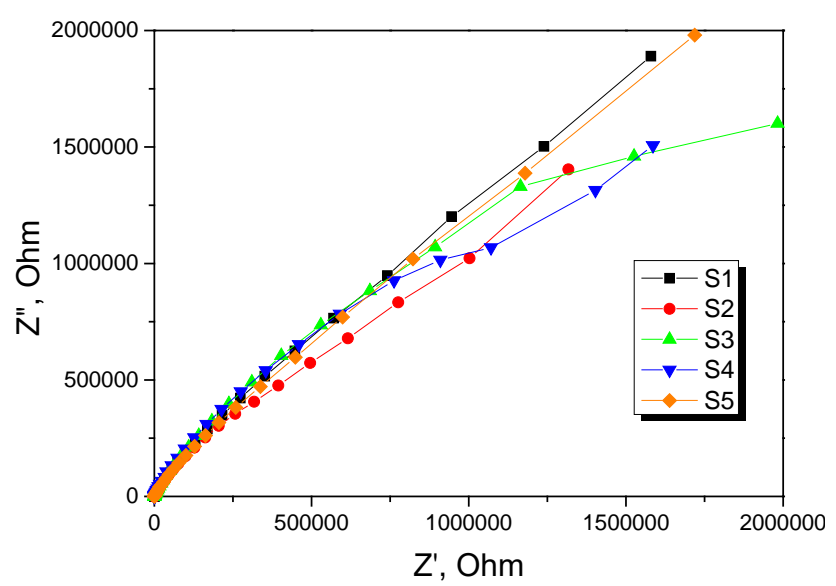

a

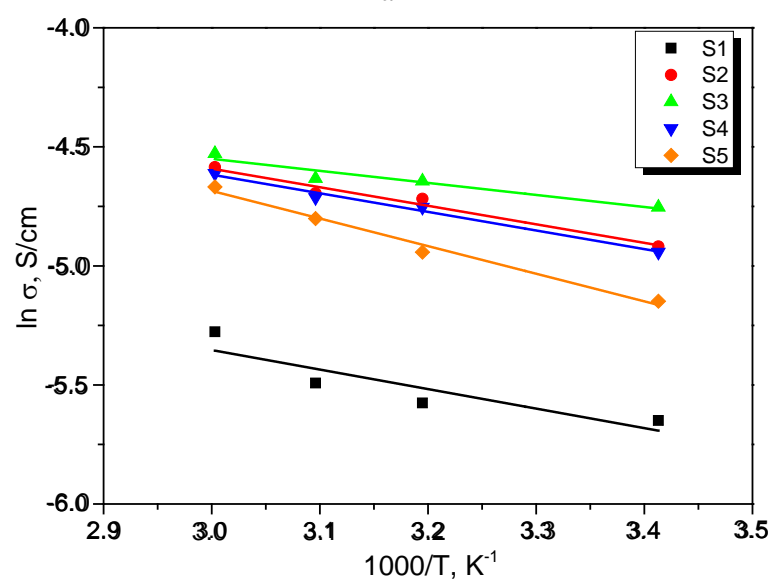

$\mathrm{b}$

Fig. 6. $a-$ Nyquist curves for the samples $\mathrm{S} 1$-S5; $\mathrm{b}$ - temperature dependence of proton conductivity in Arrhenius coordinates

Table 2. Proton conductivity of the membranes $(\mathrm{mS} / \mathrm{cm})$ at different temperatures

\begin{tabular}{|c|c|c|c|c|c|}
\hline Sample & $20^{\circ} \mathrm{C}$ & $40^{\circ} \mathrm{C}$ & $50^{\circ} \mathrm{C}$ & $60^{\circ} \mathrm{C}$ & $E_{\mathrm{a}}, \mathrm{eV}$ \\
\hline S1 & 3.52 & 3.79 & 4.12 & 5.11 & 0.149 \\
\hline S2 & 7.31 & 8.93 & 9.14 & 10.2 & 0.128 \\
\hline S3 & 8.62 & 9.62 & 9.73 & 11.2 & 0.126 \\
\hline S4 & 7.14 & 8.62 & 8.98 & 9.94 & 0.129 \\
\hline S5 & 5.81 & 7.14 & 8.22 & 9.39 & 0.132 \\
\hline
\end{tabular}

In Fig. $6 \mathrm{~b}$ the temperature dependence of proton conductivity of the samples in the coordinate's $\ln \sigma-1 / T$ is presented. The linear form of these dependencies with a regression coefficient close to 1 confirms that the change in proton conductivity with increasing temperature is of the Arrhenian character. The calculated activation energy values are comparable to the activation energies of similar systems reported in the literature. The activation energy of Nafion 117 equilibrated with liquid water was reported to vary from 9 to $14 \mathrm{~kJ} / \mathrm{mol}(0.090-0.145 \mathrm{eV})[19,20]$ while those for Nafion 120 [21] and Nafion 112 [22] are close to
$15 \mathrm{~kJ} / \mathrm{mol}(0.155 \mathrm{eV})$. In [23], the activation energy of proton conductivity of the hybrid organic-inorganic composites based on sulfur-containing styrene copolymers and allyl glycidyl ether and tetraethoxysilane was found to be $24.5 \mathrm{~kJ} / \mathrm{mol}(0.254 \mathrm{eV})$.

The proton conductivity of hybrid organic-inorganic membranes increases compared to the proton conductivity of the polymer membrane without the addition of SGS (Fig. 7). This can be explained by the formation of a hybrid structure that promotes proton mobility through proton channels saturated with unbound water capable to hydrate sulfo and $\mathrm{Si}-\mathrm{OH}$ groups. However, with the continued growth of the added sol-gel system, a decrease in proton conductivity is observed. This coincides with the greater hydrophobicity of the S5 sample. Yaroslavtsev A. and coauthors obtained similar results $[24,25]$. Researchers have suggested that the introduction of a small amount of inorganic nanoparticles into the polymer matrix leads to the expansion of pores and, consequently, the expansion of the connecting channels. Since the channels determine proton conductivity, in this case it increases. The decrease in proton conductivity with the increase in the content of the inorganic component was explained by the higher filling, "clogging" of the proton-conducting channels, and the decrease in pore volume when filling the channels with nanoparticles.

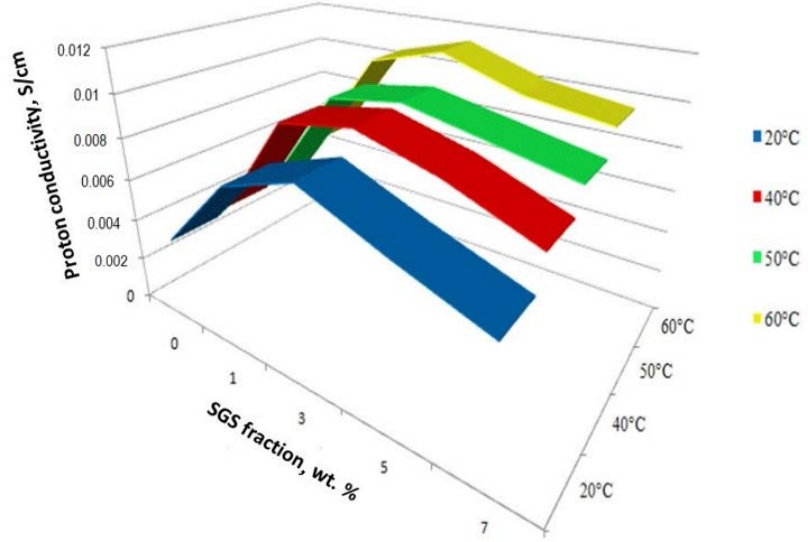

Fig. 7. Proton conductivity of the samples $\mathrm{S} 1-\mathrm{S} 5$ as a function of temperature and added SGS amount

The results of impedance measurements showed that the polymeric and organic-inorganic membranes have a sufficiently high proton conductivity caused by a high concentration of mobile protons in the bulk of the material. It is ensured by the presence of functional groups $-\mathrm{SO}_{3} \mathrm{H}$ and noncondensed silanol groups in the material. The change in proton conductivity as a function of temperature is caused by the change in the concentration of charge carriers, an increase in their mobility, and a diffusion coefficient. The activation energy of ionic displacement was found to be $0.126-0.149 \mathrm{eV}$.

\section{CONCLUSIONS}

Polyacrylate and polyacrylate/silica membranes were synthesized using UV-initiated polymerization and sol-gel process in situ based on relatively inexpensive starting materials. An increase in silica content causes a decrease in the packing density and an increase in the structural heterogeneity of the membranes, which in turn leads to an 
increase in proton conductivity, which reaches the value of $1.12-10^{-2} \mathrm{Sm} / \mathrm{cm}$ at $60^{\circ} \mathrm{C}$. Such values of the proton conductivity of the developed membranes are comparable to those for Nafion membranes, which are considered as the state-of-the-art ones. At the same time the proposed way of synthesis of organic-inorganic membranes using sol-gel method is easier, less costly, and more environmentally friendly as compared with the method of fabrication of fluorinated membranes. In addition, the membranes are based on relatively inexpensive starting materials. Thus, the obtained materials can be recommended for further research in order to develop high-efficiency ion-exchange and proton-conducting membranes.

\section{REFERENCES}

1. Wannek, C., Lehnert, W., Mergel, J. Membrane Electrode Assemblies for High-temperature Polymer Electrolyte Fuel Cells Based on Poly(2,5-benzimidazole) Membranes with Phosphoric Acid Impregnation via the Catalyst Layers Journal of Power Sources $192(2)$ 2009: pp. $258-266$.

https://doi.org/10.1016/j.jpowsour.2009.03.051

2. Wang, Y., Chen, K.S., $\quad$ Mishler, J., Cho, S.C., Adroher, X.C. A Review of Polymer Electrolyte Membrane Fuel Cells: Technology, Applications, and Needs on Fundamental Research Applied Energy 88 (4) 2011: pp. $981-1007$.

https://doi.org/10.1016/j.apenergy.2010.09.030

3. Shamim, S., Sudhakar, K., Choudhary, B. Anwar, J. A Review on Recent Advances in Proton Exchange Membrane Fuel Cells: Materials, Technology and Applications Advances in Applied Science Research 6(9) 2015: pp. 89-100.

https://www.scopus.com/record/display.uri?eid=2-s2.085040323599\&origin=inward\&txGid=af4a2a8a7f6ab87d95e 0234b4eb4c60a

4. Sun, X., Simonsen, S.C., Norby, T., Chatzitakis, A. Composite Membranes for High Temperature PEM Fuel Cells and Electrolysers: A Critical Review Membranes 9 (7) 2019: pp. 83. https://doi.org/10.3390/membranes9070083

5. Mosa, J., Duran, A., Aparicio, M. Sulfonic AcidFunctionalized Hybrid Organic-inorganic Proton Exchange Membranes Synthesized By Sol-Gel Using 3Mercaptopropyl Trimethoxysilane (MPTMS) Journal of Power Sources 297 2015: pp. 208-216. https://doi.org/10.1016/j.jpowsour.2015.06.119

6. Li, S., Liu, M. Synthesis and Conductivity of ProtonElectrolyte Membranes Based on Hybrid Inorganic-Organic Copolymers Electrochimica Acta 48 (28) 2003: pp. $4271-4276$.

https://doi.org/10.1016/j.electacta.2003.08.002

7. Lebedeva, O., Malahova, E., Sipkina, E., Chesnokova, A., Kuzmin, A., Maksimenko, S., Pozhidaev, Y, Rzhechitskiy, A., Raskulova, T., Ivanov, N. Ion Exchange Membranes Based on Silica and Sulfonated Copolymers of Styrene with Allyl Glycidyl Ether Petroleum Chemistry 57 (9) 2017: pp. 763-769.

https://doi.org/10.1134/S0965544117090067

8. Demydova, K., Horechyy, A., Yevchuk, I., Demchyna, O. The Influence of the Hydrophobic Component Content on the Properties of Hybrid Polymer-Inorganic Membranes Chemistry \& Chemical Technology 12 (1) 2018: pp. $58-63$.

\section{https://doi.org/10.23939/chcht12.01.058}

9. Zhyhailo, M., Yevchuk, I., Yatsyshyn, M., Korniy, S., Demchyna, O., Musiy, R., Raudonis, R., Zarkov, A., Kareiva, A. Preparation of Polyacrylate/Silica Membranes for Fuel Cell Application by in situ UV Polymerization Chemija 31 (4) 2020: pp. 247-254.

https://doi.org/10.6001/chemija.v31i4.4321

10. Ying, L., Jiang-Hong, G., Zi-Long, T., Yu-Sheng, $X$. Temperature-Independent Activation Energy for Ionic Conduction of Zirconia Based Solid Electrolytes Acta Physico-Chimica Sinica 17 (09) 2001: pp. $792-796$. http://www.whxb.pku.edu.cn/EN/10.3866/PKU.WHXB2001 0906

11. Kim, D., Park, H., Rhim, J., Lee, Y. Preparation and Characterization of Crosslinked $\mathrm{PVA} / \mathrm{SiO}_{2}$ Hybrid Membranes Containing Sulfonic Acid Groups for Direct Methanol Fuel Cell Applications Journal of Membrane Science $240(1-2)$ 2004: pp. 37-48. https://doi.org/10.1016/j.memsci.2004.04.010

12. Čiuladienė, A., Beganskiene, A., Senvaitiene, J., Kareiva, A. Study of Red Iron Paints for Rubrics and Miniatures: Accelerated Aging and Analytical Data Materials Science (Medžiagotyra) 27 (1) 2021: pp. $77-83$. https://doi.org/10.5755/j02.ms.25190

13. Maeda, S., Fujiwara, Y., Sasaki, C., Kunimoto, K. Structural Analysis of Microbial Poly $(\varepsilon-\mathrm{L}-$ Lysine)/Poly(Acrylic Acid) Complex by FT-IR, DSC, and Solid-state ${ }^{13} \mathrm{C}$ and ${ }^{15} \mathrm{~N}$ NMR Polymer Journal 44 2012: pp. $200-203$. https://doi.org/10.1038/pj.2011.108

14. Stadniy, I., Konovalova, V., Samchenko, Y., Pobigay, G., Burban, A., Ulberg, Z. Development of Hydrogel Polyelectrolyte Membranes with Fixed Sulpho-Groups via Radical Copolymerization of Acrylic Monomers Materials Sciences and Applications 2(4) 2011: pp. 270-275. doi: 10.4236/msa.2011.24035

15. Saini, B., Sinha, M., Dash, S. Mitigation of HA, BSA and Oil/Water Emulsion Fouling of PVDF Ultrafiltration Membranes by $\mathrm{SiO}_{2}$-g-PEGMA Nanoparticles Journal of Water Process Engineering 30 2019: pp. 100603. https://doi.org/10.1016/j.jwpe.2018.03.018

16. Garskaite, E., Karlsson, O., $\quad$ Stankeviciute, Z., Kareiva, A., Jones, D., Sandberg, D. Surface Hardness and Flammability of $\mathrm{Na}_{2} \mathrm{SiO}_{3}$ and $\mathrm{Nano}_{-} \mathrm{TiO}_{2}$ Reinforced Wood Composites RSC Advances 9 2019: pp. 27973-27986. https://doi.org/10.1039/C9RA05200C

17. Mammeri, F., Bourhis, E., $\quad$ Rozes, L., Sanchez, C. Mechanical Properties of Hybrid Organic-Inorganic Materials Journal of Materials Chemistry 15 (35-36) 2005: pp. $3787-3811$. https://doi.org/10.1039/B507309J

18. Martwiset, S., $\quad$ Chaisaward, K., $\quad$ Treepet, S., Tayraukham, P. Proton Conducting Membranes Based on Poly(Acrylonitrile-co-Styrene Sulfonic Acid) and Imidazole International Journal of Hydrogen Energy 42 (10) 2017: pp. 6918-6925. https://doi.org/10.1016/j.ijhydene.2017.02.130

19. Zawodzinski, T., $\quad$ Gottesfeld, S., $\quad$ Shoichet, S., McCarthy, T. The Contact Angle Between Water and the Surface of Perfluorosulphonic Acid Membranes Journal of Applied Electrochemistry 23 1993: pp. 86-88. https://link.springer.com/article/10.1007/BF00241582 
20. Dimitrova, P., Friedrich, K., Vogt, B., Stimming, U. Transport Properties of Ionomer Composite Membranes for Direct Methanol Fuel Cells Journal of Electroanalytical Chemistry 532 2002: pp. 75-83.

https://www.cheric.org/research/tech/periodicals/view.php?s eq $=398907$

21. Siroma, Z., Kakitsubo, R., $\quad$ Fujiwara, N., $\quad$ Ioroi, T., Yamazaki, S.I., Yasuda, K. Depression of Proton Conductivity in Recast Nafion (R) Film Measured on Flat Substrate Journal of Power Sources $189(2)$ 2009: pp. 994-998.

https://www.cheric.org/research/tech/periodicals/view.php?s eq $=811373$

22. Halim, J., Buchi, F., Haas, O., Stamm, M., Scherer, G. Characterization of Perfluorosulfonic Acid Membranes by Conductivity Measurements and Small-Angle X-ray Scattering Electrochimica Acta 39 1994: pp. 1303-1307.
https://doi.org/10.1016/0013-4686(94)E0051-Z

23. Malakhova, E., $\quad$ Raskulova, T., $\quad$ Lebedeva, O., Chesnokova, A., Pozhidaev, Y. New Proton-Conductive Membranes for Electromembrane Processes International Conference on Applied Mechanics, Mathematics, Modeling and Simulation (AMMMS 2018). 2018: pp. 322-326. https://doi.org/10.12783/dtcse/ammms2018/27283

24. Yaroslavtsev, A., Nikonenko, V. Zabolotskyi, V. Ion Transfer in Ion-Exchange and Membrane Materials Uspekhi Khimii 72 (5) 2003: pp. 438-470. https://doi.org/10.1070/RC2003v072n05ABEH00079720

25. Yaroslavtsev, A., Dobrovolsky, Y., Shaglaeva, N., Frolova, L., Gerasimova, E., Sanginov, E. Nanostructured Materials for Low-Temperature Fuel Cells Uspekhi Khimii 81(3) 2012: pp. 191-220. https://doi.org/10.1070/RC2012v081n03ABEH004290

(c) Grigoraviciute-Puroniene et al. 2022 Open Access This article is distributed under the terms of the Creative Commons Attribution 4.0 International License (http://creativecommons.org/licenses/by/4.0/), which permits unrestricted use, distribution, and reproduction in any medium, provided you give appropriate credit to the original author(s) and the source, provide a link to the Creative Commons license, and indicate if changes were made. 